\title{
THE MANAGEMENT OF CONGENITAL OESOPHAGEAL ATRESIA AND TRACHEO-OESOPHAGEAL FISTULA
}

\author{
BY \\ KEITH D. ROBERTS, IVO J. CARRE, AND JAMES McN. INGLIS \\ From the Children's Hospital, Birmingham
}

(RECEIVED FOR PUBLICATION SEPTEMBER 9, 1954)

Interest in the surgical treatment of congenital atresia of the oesophagus was aroused in this country by the publication of Franklin's paper (1947) in which he reported two infants with oesophageal atresia and tracheo-oesophageal fistula successfully operated on by the extra-pleural approach. The fistula was closed and primary oesophageal anastomosis was performed. Franklin estimated the occurrence of this abnormality to be 1 in 2,500 births.

Before this Ladd in Boston had developed a multiple-stage operation which involved extrapleural closure of the fistula, exteriorization of the upper oesophageal segment, and gastrostomy ; this was later followed by the construction of an antethoracic oesophagus. Attempts to treat such cases by gastrostomy alone had been unsuccessful, as aspiration of mucus into the bronchial tree (followed by atelectasis and infection) was not prevented.

Haight (1944) reported a series of infants in whom closure of the fistula and primary oesophageal anastomosis had been done; a similar successful one-stage operation was published by Gross and Scott (1946).

Belsey' and Donnison (1950) operated on 10 infants with five survivals, and estimated the occurrence to be 1 in 800 births.

Gross (1953) has, since 1946, attempted in all cases to obtain a primary oesophageal anastomosis. In instances where this has not been possible the stomach has been brought into the right hemithorax via the oesophageal hiatus and an immediate oesophago-gastrostomy done. He has operated on 161 infants between 1946 and 1952, with 78 survivals, a mortality rate of $52 \%$.

Belsey (1954) has now operated on a total of 28 infants with 13 operative deaths (mortality rate $46 \%$ ). He performed cervical oesophagostomy and gastrostomy in two cases, one of which died. The remainder were treated by primary anastomosis. Of the 13 deaths, three were due to congenital heart disease incompatible with further survival; three died from leaks from the oesophagus, two from the suture line and one from an area of avascular necrosis further down; two died from peripheral circulatory failure due to dehydration; five died from post-operative bronchial obstruction.

\section{Diagnosis}

The early recognition of oesophageal atresia is of the greatest importance with regard to the ultimate prognosis, and the condition may in the first instance be suspected if fine frothy mucus at the mouth is persistently produced; the foam is commonly blood-stained and may be bile-stained if a fistula exists between the lower oesophageal segment and the trachea. Cyanotic attacks and coughing occur if feeds are attempted. On examination moist adventitious sounds with diminished air entry over the right upper lobe are heard, and there is often abdominal distension (which may mimic intestinal obstruction) due to air being forced through the fistula into the stomach.

Confirmatory evidence is obtained from inability to pass an oesophageal catheter. This sign may be misleading as the catheter may coil up in the upper pouch or may pass freely into the stomach when there is merely a fistula with no atresia.

Radiological examination shows gas in the alimentary tract (unless there is no fistula between the trachea and lower oesophageal segment) but no fluid levels on the erect film. There is frequently atelectasis of the right upper lobe (present in half of our series; see Table II). The upper oesophageal pouch is outlined by instilling "lipiodol" through an oesophageal catheter.

VARIETIES OF THE ABNORMALITY.-Six varieties of the abnormality (Fig. 1) have been described by Gross (1953). Group C, the commonest type, constituted $90 \%$ of Gross's series. From observations on 14 recent cases at the Children's Hospital, Birmingham, it would seem to us that Group C can be further subdivided (see Fig. 2). 


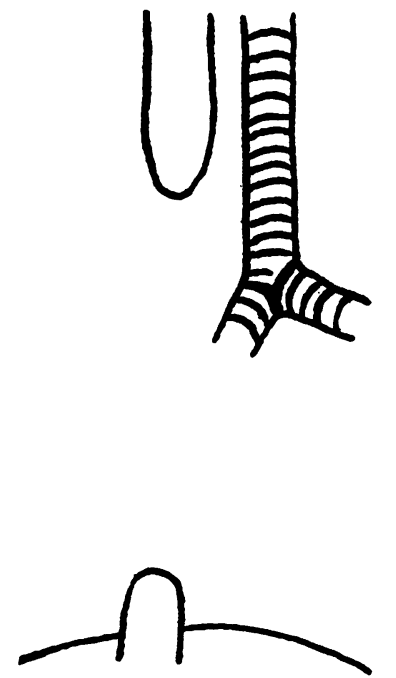

GROUP A

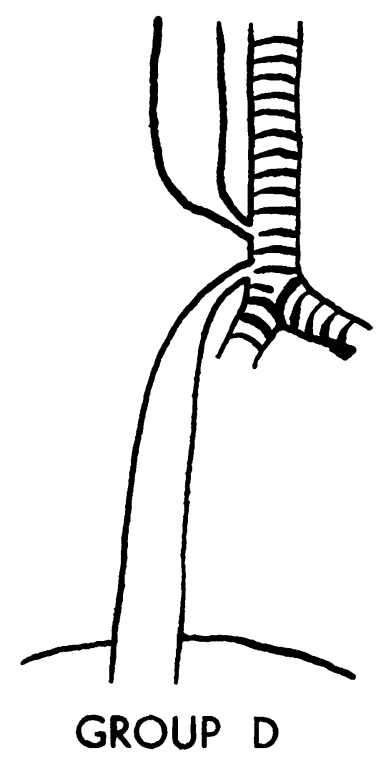

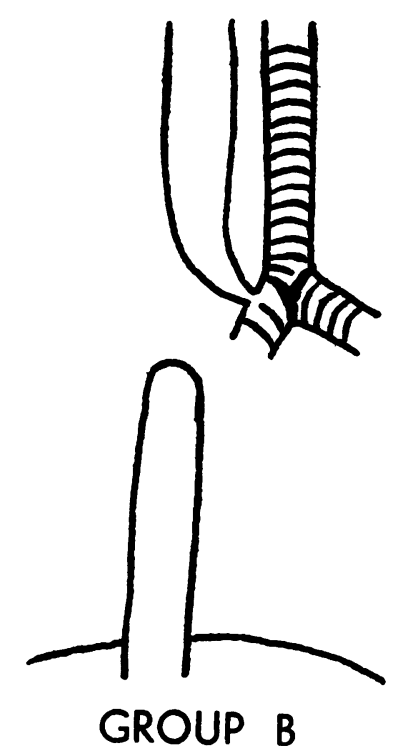

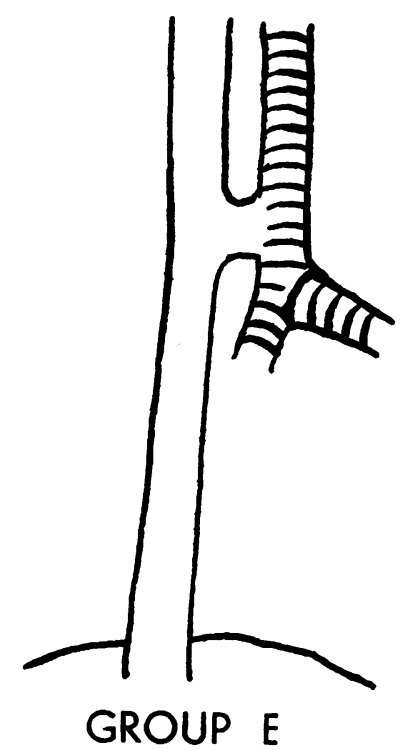

FIG. 1 (modified, after Gross).
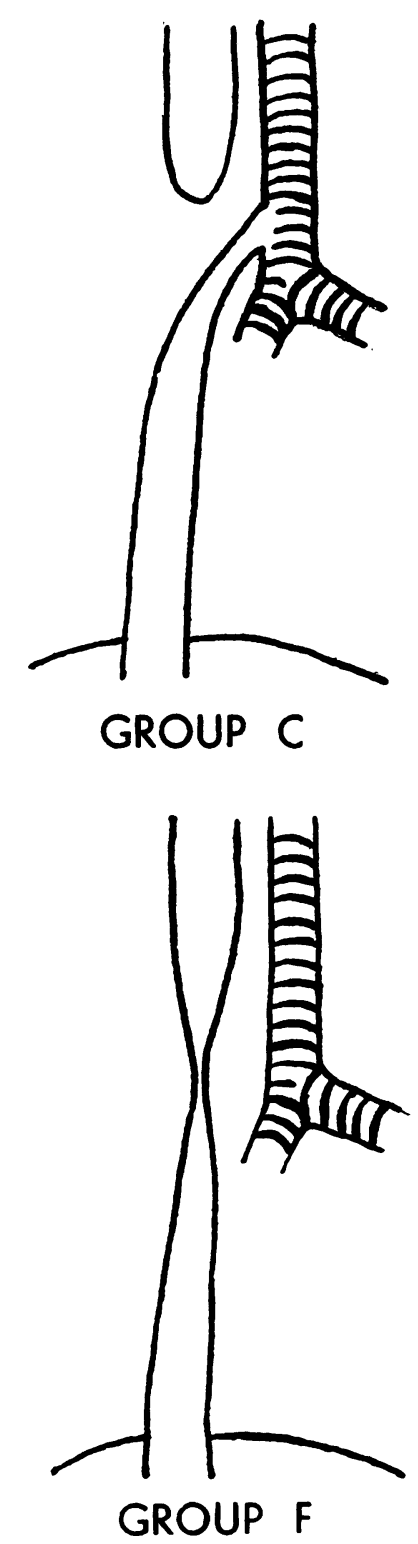

Group $C(i)$.- The fistula enters the bifurcation of the bronchus, and there is a considerable length of atresia; these cases are relatively unfavourable for primary oesophageal anastomosis (nine cases).

Group $C$ (ii).-The fistula enters the trachea high up and the upper oesophageal segment overlaps the fistula; these cases are very favourable for anastomosis (five cases).

\section{Pre-operative Preparation}

Many of these infants are unfit for operation on admission. Preparation must include drainage of the bronchial tree. This is effected by repeated aspiration of the pharynx with a small catheter attached to a suction apparatus or if necessary a laryngoscope is passed and intratracheal suction employed. The evacuation of mucus is assisted 


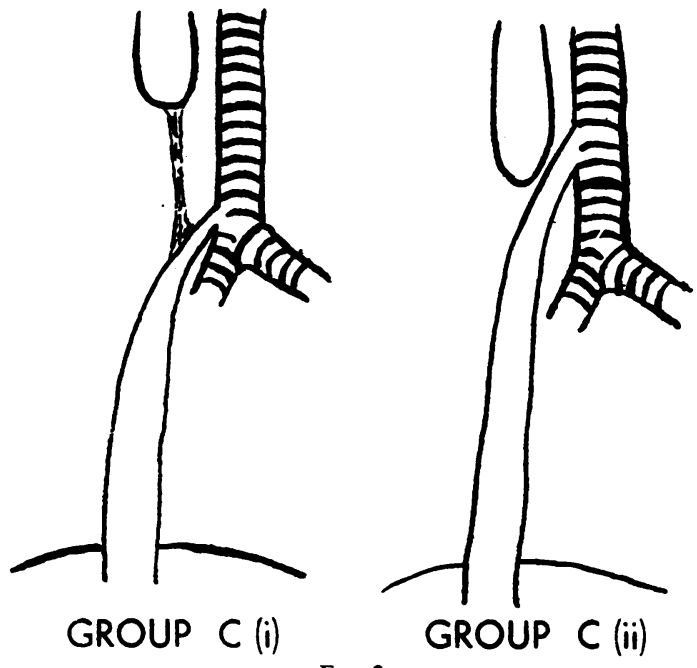

Fig. 2.

by raising the foot of the cot. Gross (1953) recommends that the infant should be kept in a semisitting position to prevent regurgitation of gastric juice through the fistula into the bronchial tree. Since the cardia is presumably competent there is no reason why much gastro-oesophageal regurgitation should occur, and we have not observed any untoward complication from such a happening; indeed, the advantages of the "head-down" position in clearing the invariably "wet" bronchial tree seem to us fully to justify the slight theoretical risk of regurgitation. Should cyanosis or evidence of respiratory embarrassment be present the infants are nursed in an oxygen tent.

Antibiotic therapy is instituted as early as possible. Soluble penicillin is given six-hourly and, because of the likelihood of infection with Gramnegative or other penicillin-resistant organisms, it has been our routine to give streptomycin as well. Vitamin $K$ is given daily in a dose of $10 \mathrm{mg}$. by intramuscular injection.

As these infants are only 1 or 2 days old, correction of dehydration with parenteral fluids is rarely indicated ; should it be considered necessary, then fluids may be given intravenously, or, preferably at this stage, by subcutaneous infusion with the addition of hyaluronidase (see post-operative treatment).

\section{ANAESTHESIA}

The advantages of general anaesthesia for these cases are so great that whenever possible this method should be used in preference to local.

No premedication is necessary or desirable and before anaesthesia is induced oro-tracheal intuba- tion with a size 0 or 1 Magill tube is carried out. Tracheal suction is then employed to remove all mucus from the bronchial tree and anaesthesia begun, using ether and oxygen, via the tube. Induction is rapid and as the respirations become regular they are assisted by manual compression of the breathing bag and a baby size Waters' canister is introduced into the circuit. Oxygen flow is kept high (8-10 litres/minute) and the carbon dioxide is gradually washed out by hyperventilation. This technique readily produces an apnoeic patient and this is maintained throughout the operation so that the respiration is completely controlled.

After the chest is closed, the addition of a small amount of carbon dioxide to the circuit will induce spontaneous respiration again.

Such small infants are poikilothermic and readily overheat if electric blankets are used on the operating table. The rectal temperature may be allowed to fall $2-3^{\circ} \mathrm{F}$. during the operation provided that the child is re-warmed before he is returned to the ward.

Post-operative tracheal suction is employed before removal of the tube and the infants are returned to the ward with a nasal oxygen catheter in situ.

\section{Technical Operative Considerations}

Operative details have been fully covered by the various authors quoted in this paper, but we believe that certain points are worthy of mention. It is our practice to use a right thoracotomy transpleural approach and we consider it preferable to resect the fourth rib rather than employ an interspace incision, as this avoids overstretching of the thoracic cage.

Simple ligation of the fistula should not be employed, as this tends to leave a stump forming a "tracheal diverticulum" in which infection may arise and lead to perforation and further fistula formation. The oesophagus must be disconnected flush with the trachea, which is then repaired with interrupted 0000 silk Blalock sutures.

Various methods of performing the anastomosis have been suggested (Gross and Scott, 1946) ; Gross (1953) favours the method of Haight (1944) in which the whole thickness of the distal oesophageal segment is sutured to the mucosa of the upper segment and the muscular coat of the latter is then sutured over the anastomosis. Belsey and Donnison (1950) stress their belief that the lower oesophageal segment derives most of its blood supply from the trachea, and state that it should be trimmed back until free bleeding occurs. In 
our experience the only trimming of the distal segment necessary is that required to obtain a good lumen. The most important factor in the whole operation is to secure an anastomosis which is not under tension. To this end adequate mobilization of both segments is necessary, and the suturing should be done while diaphragmatic movement is abolished. We have adopted a method of anastomosis using a single layer of 0000 Blalock sutures (interrupted) through all coats in the anterior and posterior walls ; closure is adequate by this means, and should the tension be so great that sutures "cut out" then a primary anastomosis is not feasible and some other method should be employed. Wherever possible a primary anastomosis has been performed in our patients, but in three closure of the fistula, cervical oesophagostomy, and gastrostomy were employed. Two of these babies survived, and restoration of continuity by an oesophago-gastrostomy has been effected successfully (Table II).

Provided the anaesthetist maintains inflation of the lung while the chest is being closed, there would appear to be little indication for pleural drainage by an intercostal tube connected to an underwater seal. Such tubes are difficult to manage post-operatively in small infants and have not been used by us as a routine. In our series there has been only one post-operative empyema which responded satisfactorily to aspirations ("Post-operative Complications"). One infant developed a clotted haemothorax despite the use of an intercostal drain, and a second thoracotomy was necessary to evacuate the clot.

Most of our early cases have been treated by withholding oral feeds for five post-operative days, fluid and caloric requirements being provided parenterally. A routine gastrostomy as advised by Gross (1953) has much to commend it ; it permits early feeding with an adequate caloric intake and maintenance of nutrition. Nursing is easier and intravenous therapy, with its attendant difficulties in a small infant and the possibility of electrolyte imbalance, is avoided. Latterly we have done a Stamm gastrostomy on the first or second post-operative day under local anaesthesia, and have been impressed with the progress made by such infants compared with our earlier patients.

\section{Post-operative Care}

The infant is nursed in the "head-down" position to assist drainage of mucus from the bronchial tree. This posture is maintained until it is considered that the infant is able to clear his own secretions adequately by coughing. Other important nursing considerations are the maintenance of a constant warmed external environment, combined with as little handling and disturbance as possible. These latter precautions apply particularly to premature infants. The airway should be aspirated as required; if necessary the trachea should be intubated and sucked out. Post-operative intubation and suction have been found to lead to marked improvement in instances where mucus retention has been troublesome. Cyanosis due to poor respiratory movements and/or atelectasis is treated by nursing the infant in an oxygen tent.

Valvular tracheal obstruction at the site of the fistula due to a crescentic fold of mucous membrane has been reported (Franklin and Graham, 1953). Evidence of inspiratory obstruction demands tracheal intubation and an attempt to break down any fold. Owing to the small size of the infant's trachea, bronchoscopy is not practicable.

Antibiotic treatment, started before operation, is continued. In those cases with a gastrostomy the penicillin and streptomycin may be augmented or replaced by other antibiotics such as chloramphenicol or aureomycin given through the gastrostomy tube. Sedation is desirable to allay undue restlessness although the prejudicial effect of crying on the oesophageal suture line has probably been exaggerated. Sodium phenobarbitone, in doses of $\frac{1}{8}$ to $\frac{1}{4}$ grain, given eight-hourly by intramuscular injection, has proved satisfactory. Over-sedation and drugs producing depression of the cough reflex should be avoided. Vitamin $\mathbf{K}$ injections are continued for five days after operation; the need for this is largely offset in those babies receiving early milk feeds via a gastrostomy, and in these cases injections are given for the first two post-operative days only.

Routine portable chest radiographs are taken daily for the first five days after operation and thereafter as indicated. Careful watch should be kept for a hydropneumothorax developing on the second or third day, as this strongly suggests leakage from the oesophageal suture line.

FEEDING SCHEME.-Based on our experience the following scheme is suggested for feeding these infants.

Infants with No Gastrostomy.-Oral feeds are withheld for five days. All necessary fluid requirements are given parenterally. Newborn infants tolerate excess fluids badly and strict precautions are necessary to avoid over-hydration. The fluid requirements during the first week of life may be 
calculated using the formula $\frac{\text { age in days }}{7} \times 2 \frac{1}{2} \mathrm{oz}$. I lb. body weight/day, for full-term infants. Thereafter fluid requirements are assessed as $2 \frac{1}{2} \mathrm{oz}$./lb. body weight/day. In the case of premature babies a similar but more gradual increase in feeds is employed, the aim in these infants being to attain a fluid intake of $3 \mathrm{oz}$./lb. body weight/day by the fourteenth day of life.

Fluids are administered intravenously through a Keith's needle. This is inserted into the long saphenous vein at the ankle before operation and can then be used to give any intravenous therapy required during the operation. Because the daily fluid requirements of these babies are so small it often proves impossible to maintain a constant drip infusion over a period of 24 hours. In these instances fluid is either run in from a drip during three four-hourly periods, or is given by a "shot" from a syringe. We have not found scalp vein infusions satisfactory for these cases. Subcutaneous infusions with hyaluronidase are unsuitable for giving blood or plasma, and for this reason have not been employed as a routine.

The calculated fluid requirements may be given as $5 \%$ dextrose and $1 / 5$ isotonic saline solution to a maximum daily intake of $500 \mathrm{ml}$. Any additional fluid needed is given as $5 \%$ dextrose solution. An alternative, and possibly more satisfactory, routine is to give $15 \mathrm{ml}$./lb. body weight/day as plasma. Because of the sodium chloride content of plasma the remainder of the daily fluid intake is given as $5 \%$ dextrose and $1 / 5$ isotonic saline solution to a maximum of $100 \mathrm{ml}$. and thereafter as $5 \%$ dextrose solution. It has been our impression that a small blood transfusion, calcu- lated as $10 \mathrm{ml}$./lb. body weight, is of help in procuring a satisfactory post-operative clinical course.

After five days feeds are begun by mouth and the parenteral fluids are correspondingly reduced. The complete post-operative feeding schedule is shown in Table I.

Infants with a Gastrostomy.-For 24 hours post-operatively fluids are given parenterally. The following day fluid requirements are given by gastrostomy in the form of half-strength breast milk in quantities as suggested for the seventh post-operative day in Table I. Feeds of full-strength breast milk are given on the third post-operative day at two- to three-hourly intervals, increasing to three- to four-hourly feeds by the tenth day. Oral feeds are then begun, provided examination with a "lipiodol" swallow excludes severe anastomotic stricture or recurrence of the fistula, and are supplemented at first by gastrostomy feeds. The gastrostomy tube is removed when oral feeding is well established.

\section{Post-operative CoMplications AND their TREATMENT}

Atelectasis is the commonest cause of death following operation. There are three main contributory factors, the most important being inhalation of mucus; this is lessened by the "headdown" position and frequent aspiration of the pharynx. Oedema at the site of anastomosis may cause obstruction of the oesophageal lumen and consequent "spill-over" of secretions into the trachea ; again, prophylaxis depends on postural drainage and pharyngeal aspiration. It is a marked feature at necropsy that the lung on the

TABle I

POST-OPERATIVE FEEDING SCHEDULE FOR INFANTS WITHOUT A GASTROSTOMY

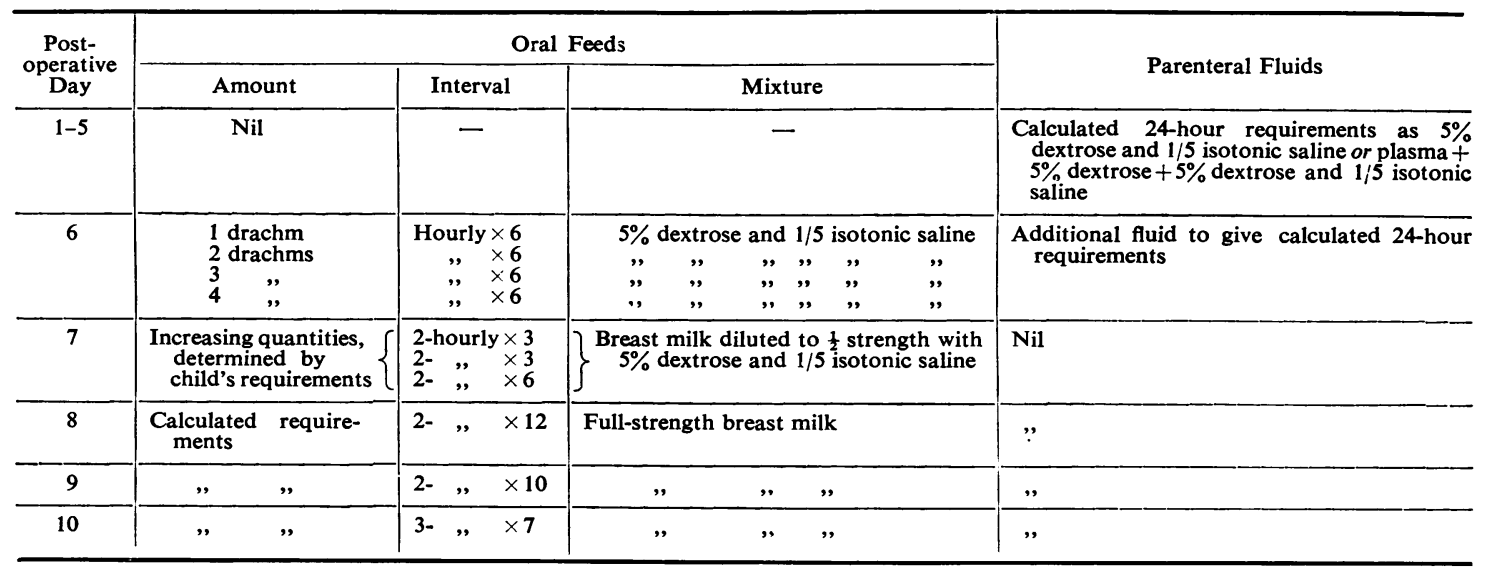


operated side is more atelectatic than the other, and we suggest that impaired chest movement may in part be responsible; as already stressed, oversedation of these infants is to be avoided, and a light dressing only should be used for the wound; we believe a rib resection preferable to an interspace incision.

Most infants have a persistent cough for several months after operation, possibly due to the sutures in the trachea. Cough, with attacks of cyanosis on feeding, should lead to the suspicion of recurrence of the fistula or the development of an oesophageal stricture. Recurrence of the fistula may be treated by gastrostomy and allowed to close spontaneously, but Gross (1953) advises operative closure of the fistula as soon as the diagnosis of recurrence is made.

G. B., a boy, was operated on at the age of 2 days, an anastomosis being effected and the fistula closed. Eleven weeks after operation he developed a cough; feeds were taken with difficulty and often associated with cyanotic attacks. A "lipiodol" swallow showed some narrowing at the site of anastomosis and "lipiodol" passed through a fistulous connexion into the trachea (Fig. 3). A gastrostomy was done; the $\Rightarrow$ fistula appeared to have closed two months iater and $\stackrel{0}{\longrightarrow}$ oral feeds were resumed. Two months after this the child was readmitted to hospital, as he was coughing 듬 during his feeds, and a "lipiodol" swallow again $\overline{\frac{\bar{m}}{7}}$ demonstrated the fistula. A right thoracotomy was $\vec{\Phi}$ done; a fistula was found passing obliquely upwards $\varrho$ from the oesophageal anastomosis to the trachea and $\mathscr{\infty}$ was closed successfully.

Belsey (1954) had had two infants in whom a $\vec{\overrightarrow{ }}$ fistula had recurred; in one the child appeared to be perfectly well until the age of 18 months, $\overrightarrow{\overrightarrow{2}}$ when a sudden vomit while sleeping in the "kneeelbow" position caused death due to flooding of $\overrightarrow{0}$ the bronchial tree. The other infant developed a total atelectasis and bronchiectasis of the left $i$ lung and failed to survive pneumonectomy. At 을 necropsy a notable feature of the fistula was its obliquity upwards from the oesophagus to the trachea, as was found in our case.

Some degree of narrowing at the site of $\stackrel{5}{\supset}$ anastomosis is not uncommon; if severe, reten- $\vec{c}$ tion of secretions occurs with "spill-over" intc or the trachea. The stricture may cure itself, but if

TABLE II

INFANTS ADMITTED TO THE CHILDREN'S HOSPITAL, BIRMINGHAM, FROM JANUARY, 1953, TO JANUARY, 1954

\begin{tabular}{|c|c|c|c|c|c|c|c|c|c|}
\hline Infant & $\begin{array}{l}\text { Age } \\
\text { in } \\
\text { Days }\end{array}$ & $\begin{array}{c}\text { Birth } \\
\text { Weight } \\
\text { (lb. oz.) }\end{array}$ & $\begin{array}{c}\text { Atelectasis } \\
\text { Pre- } \\
\text { operatively }\end{array}$ & $\begin{array}{l}\text { Other } \\
\text { Congenital } \\
\text { Defects }\end{array}$ & $\begin{array}{l}\text { Type of } \\
\text { Abnorm- } \\
\text { ality }\end{array}$ & Operation & $\begin{array}{c}\text { Post- } \\
\text { operative } \\
\text { Complications }\end{array}$ & Survival & $\begin{array}{l}\text { Cause } \\
\text { of } \\
\text { Death }\end{array}$ \\
\hline W. C. . & 2 & 712 & $\mathrm{O}$ & $\mathrm{O}$ & C (i) & $\begin{array}{l}\text { Closure of fistula } \\
\text { + anastomosis }\end{array}$ & $\begin{array}{l}\text { Oesophageal } \\
\text { stricture }\end{array}$ & & 一 \\
\hline A. C. R. & 2 & 61 & $\mathrm{O}$ & $\begin{array}{l}\text { Patent ductus arteriosus } \\
\text { Coarctation of aorta }\end{array}$ & C (i) & $\begin{array}{l}\text { Closure of fistula } \\
+ \text { anastomosis }\end{array}$ & Atelectasis & Dead & Atelectasis \\
\hline $\begin{array}{l}\text { M. R. S. } \\
\text { S. W. }\end{array}$ & $\begin{array}{l}3 \\
1\end{array}$ & $\begin{array}{c}6 \\
\text { Unknown }\end{array}$ & $\begin{array}{l}\text { R.U.L. } \\
\text { R.U.L. }\end{array}$ & $\begin{array}{c}\mathrm{O} \\
\text { Patent ductus arteriosus }\end{array}$ & $\stackrel{E}{C}$ (i) & $\begin{array}{l}\text { Closure of fistula } \\
\text { Closure of fistula } \\
+ \text { anastomosis }\end{array}$ & $\ddot{,}$ & ," & ," \\
\hline D. W. A. & 3 & 48 & $\mathrm{O}$ & Right arching aorta & C (i) & $\begin{array}{c}\text { Closure of fistula, } \\
\text { cervical oeso- } \\
\text { phagostomy, } \\
\text { gastrostomy }\end{array}$ & , & , & , \\
\hline R. W. . . & 6 & Unknown & $\begin{array}{l}\text { R.L.L. } \\
\text { L.L.L. }\end{array}$ & $\begin{array}{l}\text { Congenital obliteration } \\
\text { of common bile duct. } \\
\text { Bilateral hydroneph- } \\
\text { rosis and hydro-ureter }\end{array}$ & C (i) & $\begin{array}{l}\text { None-infant } \\
\text { moribund }\end{array}$ & 一 & , & $\begin{array}{l}\text { Broncho- } \\
\text { pneumon: }\end{array}$ \\
\hline L. B. $\quad \cdots$ & $1 \frac{1}{2}$ & 79 & $\mathrm{O}$ & $\begin{array}{l}\text { rosis and nydro-ureter } \\
\text { Right arching aorta }\end{array}$ & C (ii) & $\begin{array}{l}\text { Closure of fistula } \\
+ \text { anastomosis }\end{array}$ & $\begin{array}{l}\text { Leakage from } \\
\text { anastomosis }\end{array}$ & Alive & - \\
\hline P. S. $\quad \cdots$ & $1 \frac{1}{2}$ & Unknown & $\mathrm{O}$ & $\mathbf{O}$ & C (i) & $\begin{array}{l}\text { Closure of fistula } \\
+ \text { anastomosis }\end{array}$ & & , & \\
\hline L. L. ${ }^{1} \quad \ldots$ & 3 & 612 & R.U.L. & Right arching aorta & C (i) & $\begin{array}{l}\text { Closure of fistula, } \\
\text { cervical oeso- } \\
\text { phagostomy, } \\
\text { gastrostomy }\end{array}$ & $\begin{array}{l}\text { Right empy- } \\
\text { ema }\end{array}$ & , & - \\
\hline D. E. $\quad$. & 1 & & R.U.L. & $\mathrm{O}$ & $\mathrm{C}$ (ii) & $\begin{array}{l}\text { Closure of fistula } \\
+ \text { anastomosis }\end{array}$ & $\begin{array}{l}\text { Oesophageal } \\
\text { stricture }\end{array}$ & , & \\
\hline P. W. . . & 4 & Unknown & R.U.L. & $\mathrm{O}$ & C (ii) & $\begin{array}{l}\text { Closure of fistula } \\
+ \text { anastomosis }\end{array}$ & $\begin{array}{l}\text { Right haemo- } \\
\text { thorax. }\end{array}$ &, & \\
\hline J. A. $\quad \cdots$ & 3 & 315 & R.U.L. & $\mathrm{O}$ & C (ii) & $\begin{array}{l}\text { Closure of fistula } \\
+ \text { anastomosis }\end{array}$ & Atelectasis & Dead & Atelectasis \\
\hline G. B. ${ }^{2} \quad \ldots$ & 2 & 413 & R.U.L. & $\mathrm{O}$ & C (ii) & $\begin{array}{l}\text { Closure of fistula } \\
+ \text { anastomosis }\end{array}$ & $\begin{array}{l}\text { Recurrence of } \\
\text { fistula }\end{array}$ & Alive & 一 \\
\hline P. N. $\quad \cdots$ & 2 & 412 & $\mathrm{O}$ & $\mathrm{O}$ & $\mathrm{C}(\mathrm{i})$ & $\begin{array}{l}\text { Closure of fistula } \\
+ \text { anastomosis }\end{array}$ & Atelectasis & Dead & Atelectasis \\
\hline M. J. V. ${ }^{1}$ & 3 & 68 & R.U.L. & $\mathrm{O}$ & $C(i)$ & $\begin{array}{c}\text { Closure of fistula, } \\
\text { cervical oeso- } \\
\text { phagostomy, } \\
\text { gastrostomy }\end{array}$ & - & Alive & - \\
\hline
\end{tabular}

1 Successful reconstruction by left cervical oesophago-gastrostomy at age 14 months. ${ }^{2}$ Re-established fistula successfully closed at age $\frac{0}{\sigma}$ 7 monthe 


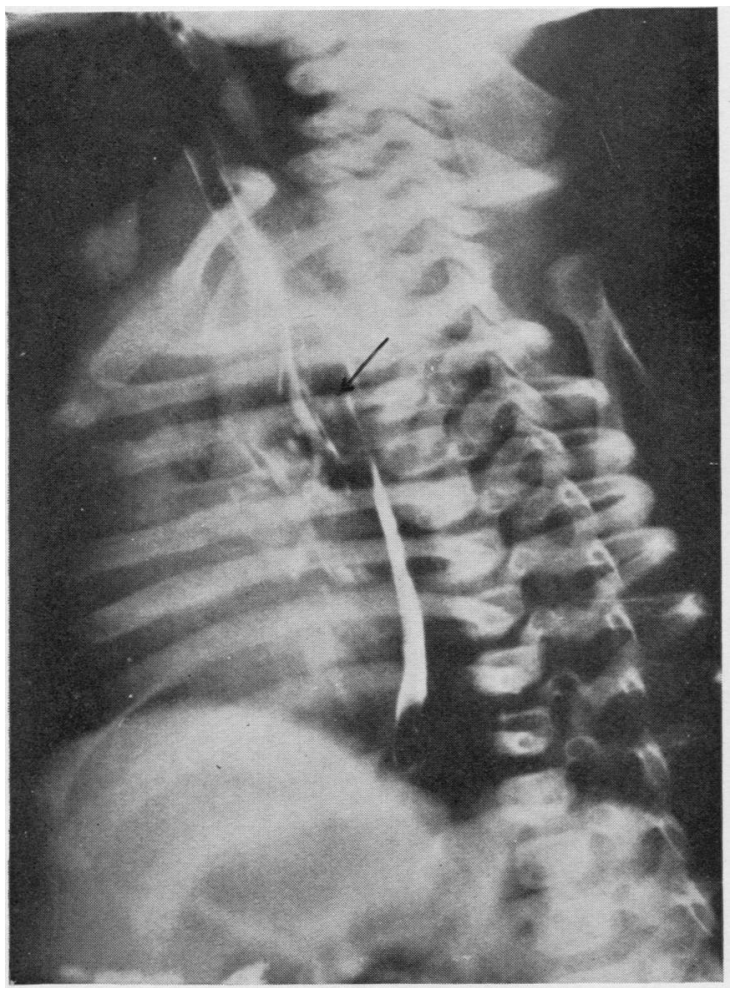

FIG. 3.-Radiograph showing the passage of "lipiodol" from the oesophagus into the trachea through a recurrence of the fistula 11 weeks after operation.

great difficulty is experienced with feeding, either a gastrostomy should be done (with later retrograde dilatation), or even excision and reanastomosis may be necessary.

D. E., a boy, was operated on at the age of 1 day. Three weeks later a cough developed, with feeding difficulty. A "lipiodol" swallow showed a considerable degree of stricture with distension of the upper oesophageal segment (Fig. 4). The child was treated conservatively and no further operative procedure has been necessary.

Leakage from the oesophageal anastomosis is almost invariably due to an anastomosis performed with undue tension. Such a complication is serious and usually the infant is unfit to withstand more than an intercostal drainage and feeding gastrostomy under local anaesthesia.

Empyema is a rare complication. The only case in this series occurring post-operatively responded to daily aspiration and intrapleural penicillin. Such a complication should always be treated by this conservative method.

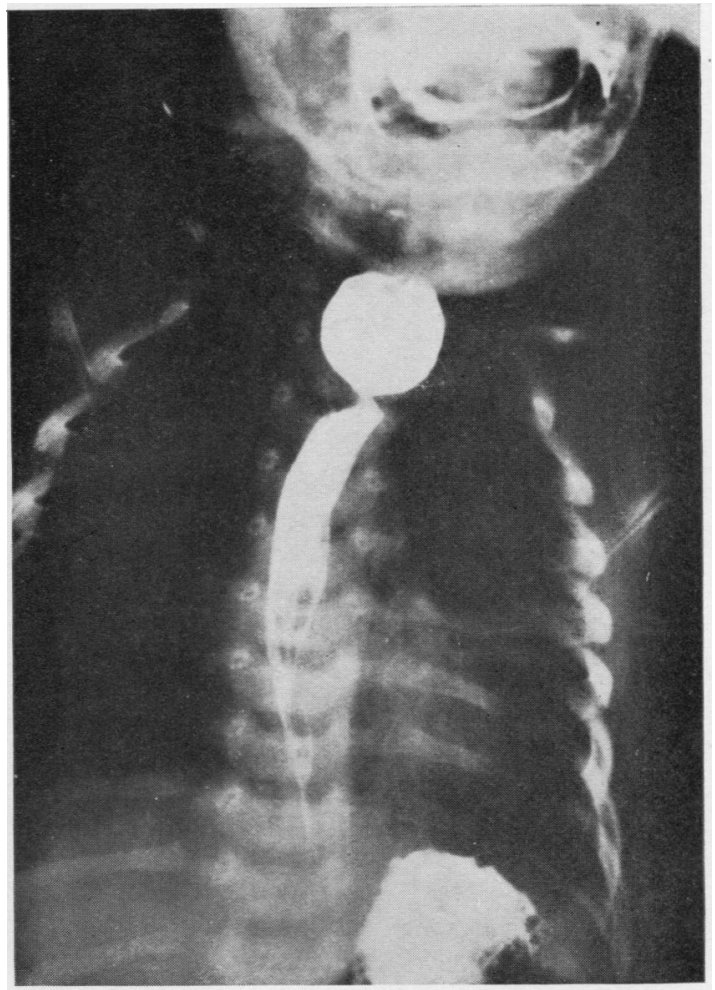

FIG. 4.-Radiograph of a "lipiodol" swallow showing a severe degree of anastonotic stricture three weeks after operation.

Haemothorax may occur if adequate vitamin $\mathrm{K}$ therapy has not been instituted. It developed in one of our cases (see Table II), necessitating a second thoracotomy to evacuate the clot.

\section{ASSESSMENT OF RESUlTS}

The scheme of management of congenital oesophageal abnormalities described was evolved after some four years' work, and used exclusively in the period shown in Table II. Out of 15 patients admitted during this time 14 underwent operation, with eight survivals, a mortality rate of $43 \%$. With further work on the prevention and treatment of post-operative atelectasis in these infants it should be possible to reduce the mortality rate still further.

\section{SUMMARY}

The diagnosis of congenital oesophageal atresia is briefly outlined.

Pre-operative preparation is chiefly directed to draining the bronchial tree of secretions and the institution of antibiotic therapy. 
The post-operative management is fully described with special reference to the prevention of atelectasis and the nutritional and fluid requirements of the infant. The chief post-operative complications are discussed together with the appropriate treatment.

A brief survey of the results at the Children's Hospital, Birmingham, is given for the period January, 1953, to January, 1954.

We are indebted to Mr. A. L. d'Abreu, under whose care these infants have been treated, for his constant advice and encouragement. Our thanks are also due to the physicians of the Children's Hospital, Birming- ham, who have referred many of these patients to $\overrightarrow{\vec{F}}$ us, to Dr. Roy Astley for the radiological examinations, and to Mr. J. G. Williamson for the photographic reproductions.

We are most grateful to Mr. R. H. R. Belsey, who, तె from his exceptional experience of this condition, has readily given us such valuable information.

\section{REFERENCES}

Belsey, R. H. R. (1954). Personal communication. and Donnison, C. P. (1950). Brit. med. J., 2, 324 Franklin, R. H. (1947). Lancet, 2, 243.

and Graham, A. J. P. (1953). Thorax, 8, 102. Gross, R. E. (1953). The Surgery of Infancy and Childhood, Saunders, Philadelphia and London.

and Scott, H. W. (1946). Surg. Gynec. Obstet., 82, 518.

Haight, C. (1944). Ann. Surg., 120, 623. 